\section{Unusual cause of parietal thoracic pain: A case report}

\section{Mohamed Labied*, Hayat Lhajoui, Najwa Touil, Omar Kacimi and Nabil Chikhaoui}

Emergency Radiology Department, Ibn Rochd University Hospital, Casablanca, Morocco

\section{Abstract}

We report the radio-clinical observation of a 21-year-old patient, referred for anterior chest parietal discomfort evolving for 3 months ago, with the notion of trauma.

The chest CT (computed tomography) scan detected a costal cartilage fracture without associated traumatic pulmonary or mediastinal changes.

This case illustrates the usefulness of imaging in the diagnosis and management of costal cartilage fractures, and for screening out differential diagnoses.

The aim of this study is to determine the interest of imaging in the study of fractures of the chrondro-costal cartilage.

Is to determine the CT value in chrondro-costal cartilage fracture.

\section{Introduction}

Costal cartilage fractures are poorly described in the literature. It is one of the possible causes of post-traumatic pain in the anterior chest wall.

Their frequency is under-evaluated, because clinical presentation is the same as a rib fracture. In light of the normality of conventional rays, the diagnosis of muscular sprain is accepted [1].

\section{Observation}

21-year-old male, without any particular medical history. Who was admitted for anterior chest pain that has been persisting for 3 months ago, with a notion of direct mechanism injury and normal chest X-ray.

Clinical examination revealed pain on palpation of the anterior extremity of the $7^{\text {th }}$ right rib without swelling or inflammatory signs.

Consideration the importance of the symptoms, a thoracic CT scan was performed, which detected a fracture of the costal cartilage and related adjacent soft tissue granulation, all without associated parenchymal or mediastinal changes (Figure 1).

\section{More Information}

*Address for Correspondence: Dr. Labied Mohamed, Radiology Intern, Emergency Radiology Department, Ibn Rochd University Hospital, Casablanca, Morocco,

Tel: +212687931785;

Email: labied.mohamed@gmail.com

Submitted: 15 June 2020

Approved: 14 July 2020

Published: 15 July 2020

How to cite this article: Labied M, Lhajoui $\mathrm{H}$ Touil N, Kacimi O, Chikhaoui N. Unusual cause of parietal thoracic pain: A case report. Arch Case Rep. 2020; 4: 046-047.

DOI: 10.29328/journal.acr.1001040

ORCiD: orcid.org/0000-0001-8873-484X

Copyright: @ 2020 Labied M, et al. This is an open access article distributed under the Creative Commons Attribution License, which permits unrestricted use, distribution, and reproduction in any medium, provided the original work is properly cited.

Keywords: Costal cartilage; Fracture; Computed tomography

\section{(2) Check for updates}

OPEN ACCESS

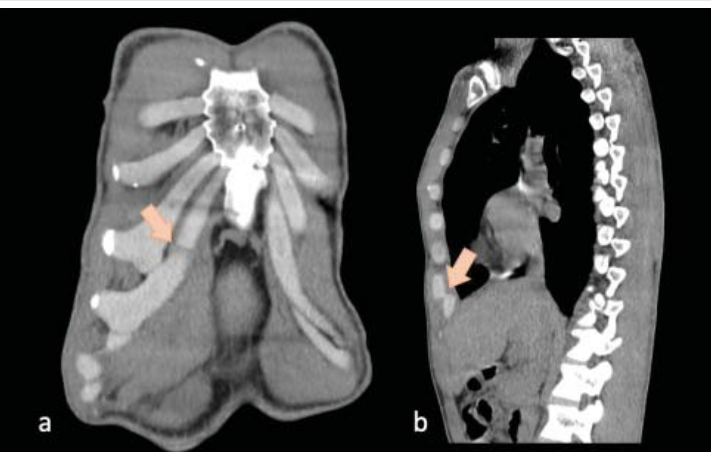

Figure 1: Coronal (a) and sagittal (b) CT reconstructions: shifted fracture of the 7 right rib costal cartilage (arrow)

\section{Discussion}

Costal cartilage fracture occurs rarely as a traumatic injury, but the frequency is probably underestimated $[1,2]$.

Two types of mechanism are implicated in costal cartilage fractures. The first is rotational and predominates at the sterno-chondral and costochondral junctions. The second is direct on the cartilage and would mainly affect the lower extremities [3].

Malghem, et al. reported a series of 15 costal cartilage 
fractures, six involved the first ribs, two involved the second, third and sixth and one involved the fourth, seventh and ninth [4].

Chronic symptoms may be caused by the inability of chondrocytes to consolidate the fracture line, compared to bone cells which induce a consolidation process usually leading to the formation of callus and remodelling of rib-bone fractures within a few weeks [5].

In most cases, the costal cartilages are not visible on x-rays, expect the irregular ossification foci that usually appears in adulthood [6].

In ultrasonography, cartilage is hypoechoic than muscle and is delimited by an echogenic anterior line with the fracture visualized as an interruption of this latter [4].

However, the costal cartilage is easily detected by CT scan. They are relatively homogeneous density (70-120 H), higher than muscle and fat, but less than bone [7]. Multiplanar reconstructions can easily visualize the fracture line of the costal cartilage. The presence of air inside the fracture can be detected. In a study reporting 15 cases of costal cartilage fractures, Malghem and al. found 4 fractures associated with the presence of air bubbles [4].

Subhas and al. team reported the value of Magnetic resonance imaging (MRI) in the diagnosis of costal cartilage fractures in a 14-case study. MRI detected the fracture line in all cases except one case where a fracture line was not clearly recognized; an edema in hyposignal T1 and hypersignal T2 was seen at the fracture site [3].

Treatment of costal cartilage fractures is symptomatic. It combines antalgics, non-steroidal anti-inflammatory, ice and a compression belt [8].

The differential diagnosis is made with other causes of anterior chest wall pain:

Tietze syndrome most often affects female young persons. The diagnosis is essentially clinical. Imaging is useful only to exclude a rhumatic disease, infection, and tumor [9]. MRI, if it were performed, would show thickening of the costal cartilage, and adjacent bone edema [10].

Costochondritis most often affects young adults older than 40 years, revealed by chest pain involving chondrosternal joints, without swelling [9].

The SAPHO syndrome corresponds to a broad spectrum of neutrophilic dermatoses, associated with aseptic osteoarticular lesions, with sterno-costal joint most frequently affected. Imaging shows hyeperostosis with bone condensations visible on the x-rays and CT scan. The STIR hypersignal in MRI indicates the inflammatory nature of this disease [11].

\section{Conclusion}

Our observation shows the value of CT in the positive diagnosis of costal cartilage fractures; a diagnosis often missed on standard radiography, and to exclude other causes of anterior chest wall pain.

\section{Patient consent}

Informed written consent for publication of clinical details was obtained from the patient.

\section{Author's contribution}

Mohamed Labied, as a corresponding author, proposed the concept and idea for the study, and wrote the manuscript.

Hayat Lhajoui contributed to the writing and preparation of the iconography.

All authors critically revised the manuscript for intellectual content and approved the final manuscript.

\section{References}

1. Griffith JF, Rainer TH, Ching AS, Law KL, Cocks RA, et al. Sonography compared with radiography in revealing acute rib fracture. AJR Am J Roentgenol. 1999; 173: 1603-1609.

PubMed: https://pubmed.ncbi.nlm.nih.gov/10584808/

2. Miles JW, Barrett GR. Rib fractures in athletes. Sports Med. 1991; 12 66-69.

PubMed: https://pubmed.ncbi.nIm.nih.gov/1925189/

3. Subhas N, Kline MJ, Moskal MJ, White LM, Recht MP. MRI evaluation of costal cartilage injuries. AJR Am J Roentgenol. 2008; 191: 129132.

PubMed: https://pubmed.ncbi.nlm.nih.gov/18562735/

4. Malghem J, Vande Berg B, Lecouvet F, Maldague B. Costal cartilage fractures as revealed on CT and sonography. AJR Am J Roentgenol. 2001; 176: 429-432

PubMed: https://www.ncbi.nlm.nih.gov/pubmed/11159088

5. Buckwalter JA, Cruess RL. Healing of the musculoskeletal tissues. In: Rockwood CA Jr, Green DP, Bucholz RW, eds. Rockwood and Green's fractures in adults, 3rd ed. Philadelphia: Lippincott, 1991: 181-222.

6. Ontell FK, Moore EH, Shepard JA, Shelton DK. The costal cartilages in health and disease. Radiographics. 1997; 17: 571-577.

7. Edelstein G, Levitt RG, Slaker DP, Murphy WA. Computed tomography of Tietze syndrome. J Comput Assist Tomogr. 1984; 8: 20-23. PubMed: https://pubmed.ncbi.nlm.nih.gov/6690519/

8. Bienvenot P, Phan C, Miquel A, Pradel C, Hammel B, et al. Les fractures du cartilage costal: un diagnostic souvent méconnu Journal de Traumatologie du Sport. 2011; 28: 107-109.

9. Kaplan T, Gunal N, Gulbahar G, et al. Painful Chest Wall Swellings: Tietze Syndrome or Chest Wall Tumor? Thorac Cardiovasc Surg. 2016; 64: 239-244.

PubMed: https://pubmed.ncbi.nlm.nih.gov/25742551

10. Volterrani L, Mazzei MA, Giordano N, Nuti R, Galeazzi M, Fioravanti A. Magnetic resonance imaging in Tietze's syndrome. Clin Exp Rheumatol. 2008; 26: 848-853

PubMed: https://pubmed.ncbi.nlm.nih.gov/19032818/

11. Nguyen MT, Borchers A, Selmi C, Naguwa SM, Cheema G, et al The SAPHO syndrome. Semin Arthritis Rheum. 2012; 42: 254-265. PubMed: https://pubmed.ncbi.nlm.nih.gov/23153960/ 09 